OPEN ACCESS

Edited by:

Flavia Bazzoni,

Università di Verona, Italy

Reviewed by:

Massimo Locati,

Università degli Studi di Milano, Italy

Cinzia Fionda,

Sapienza Università di Roma, Italy

*Correspondence:

Guo-Jun Zhao

zzhcsu@163.com

${ }^{+}$Co-first authors.

Specialty section: This article was submitted to Cytokines and Soluble Mediators in Immunity,

a section of the journal

Frontiers in Immunology

Received: 14 February 2018

Accepted: 11 May 2018

Published: 28 May 2018

Citation:

Li H, Jiang T, Li M-Q, Zheng X-L and

Zhao G-J (2018) Transcriptional

Regulation of Macrophages

Polarization by MicroRNAs.

Front. Immunol. 9:1175.

doi: $10.3389 /$ fimmu.2018.01175

\section{Transcriptional Regulation of Macrophages Polarization by MicroRNAs}

\author{
Heng $\mathrm{Li}^{1 \dagger}$, Ting Jiang ${ }^{2 \dagger}$, Meng-Qi $\mathrm{Li}^{3}$, Xi-Long Zheng ${ }^{4,5}$ and Guo-Jun Zhao ${ }^{3,4 *}$ \\ ${ }^{1}$ The Clinic Medical College, Guilin Medical University, Guilin, Guangxi, China, ${ }^{2}$ Department of Practice Educational, Office of \\ Academic Affairs, Guilin Medical University, Guilin, Guangxi, China, ${ }^{3}$ Department of Histology and Embryology, Guilin Medical \\ University, Guilin, Guangxi, China, ${ }^{4}$ Department of Biochemistry and Molecular Biology, The Libin Cardiovascular Institute of \\ Alberta, The University of Calgary, Health Sciences Center, Calgary, AB, Canada, ${ }^{5}$ Key Laboratory of Molecular Targets and \\ Clinical Pharmacology, School of Pharmaceutical Sciences, Guangzhou Medical University, Guangzhou, Guangdong, China
}

Diversity and plasticity are the hallmarks of cells from the monocyte-macrophage lineage. Macrophages undergo classical M1 or alternative M2 activation in response to the microenvironment signals. Several transcription factors, such as peroxisome proliferator-activated receptors, signal transducers and activators of transcription, CCAAT-enhancer-binding proteins, interferon regulatory factors, Kruppel-like factors, GATA binding protein 3, nuclear transcription factor- $\mathrm{KB}$, and $\mathrm{c}-\mathrm{MYC}$, were found to promote the expression of specific genes, which dictate the functional polarization of macrophages. Importantly, these transcription factors can be regulated by microRNAs (miRNAs), a group of small non-coding RNAs, which regulate gene expression through translation repression or mRNA degradation. Recent studies have also revealed that miRNAs control macrophage polarization by regulating transcription factors in response to the microenvironment signals. This review will summarize recent progress of miRNAs in the transcriptional regulation of macrophage polarization and provide the insights into the development of macrophage-centered diagnostic and therapeutic strategies.

\section{Keywords: microRNAs, transcription factors, macrophages polarization, tumor, immunity}

\section{INTRODUCTION}

Monocyte-macrophage lineage cells exist in various tissues in the body and play an important role in homeostasis, cancer, wound healing, and immune response $(1,2)$. Macrophages are derived from bone marrow-derived monocytic cells via a process of differentiation $(3,4)$. Circulating monocytes migrate into the majority of tissues in the body, where they differentiate into functionally distinct mature macrophages (4). Besides, it was also described that tissue-resident macrophages originate from yolk-sac-derived erythro-myeloid progenitors $(5,6)$. Adult Langerhans cells are derived predominantly from embryonic fetal liver monocytes with a minor contribution of yolk sac-derived macrophages (7). Monocyte-macrophage lineage cells are featured by functional diversity and plasticity. The classically activated M1 and alternatively M2 macrophages represent two extremes of a dynamic changing state of macrophage activation. In response to the microenvironment signals, macrophages can rapidly switch from one polarization state to the other $(8,9)$. It is known that the dynamic change of macrophage activation is directed by the activation of specific transcription factors, such as peroxisome proliferator-activated receptors (PPARs), signal transducers and activators of transcription (STATs), CCAAT-enhancer-binding proteins (C/EBPs), interferon 
regulatory factor (IRF), Kruppel-like factors (KLFs), GATA binding protein (GATA) 3, c-MYC, and nuclear transcription factor- $\kappa \mathrm{B}(\mathrm{NF}-\kappa \mathrm{B})(3,4)$.

M1 macrophages, also known as classically activated macrophages, can be activated by toll-like receptor (TLR) ligands, such as lipopolysaccharides (LPS) or interferon- $\gamma$ (IFN- $\gamma$ ). M1 macrophages are characterized by high antigen presentation, high expression of pro-inflammatory cytokines [e.g., interleukin (IL)-12, IL-23, and tumor necrosis factor- $\alpha$ (TNF- $\alpha$ )], and high production of reactive nitrogen intermediates and reactive oxygen intermediates. M1 macrophages are supposedly associated with inflammatory, microbicidal, and tumoricidal activities (10-12). M2 macrophages, also called alternatively activated macrophages, can be further subdivided into subsets called M2a, M2b, M2c, and M2d. The Th2 cytokines such as IL-4 and IL-13 bind to IL- 4 and IL-13 receptors to induce the formation of M2a macrophages, whereas M2b macrophages are induced by immunoglobulin complexes in combination with TLR agonists, and $\mathrm{M} 2 \mathrm{c}$ macrophages are induced by IL-10, transforming growth factor $\beta$ (TGF- $\beta$ ), or glucocorticoids (13-15). Within the tumor, macrophages are a major stromal component, where they are commonly termed tumor-associated macrophages (TAMs). TAMs exhibit functions similar to those of M2 macrophages and can be characterized as the M2d subtype (16). M2 macrophages are characterized by an IL- $12^{\text {low } I L-10^{\text {high }}}$ IL- 1 decoyR $\mathrm{R}^{\text {high }} \mathrm{IL}-1 \mathrm{RA} \mathrm{A}^{\text {high }}$ phenotype with efficient phagocytic activity, high expression of mannose and galactose receptors, high levels of scavenging molecules, and high expression of specific markers of alternative activation, such as arginase-1 (Arg-1), found in inflammatory zone 1 (Fizz1) and chitinase-3-like protein 3 (Ym1). M2 macrophages are responsible for tuning inflammatory responses, adaptive immunity, parasite infection, tissue remodeling and repair, scavenge debris, and promoting angiogenesis and tumor progression (17-20). Transcription factors are the key molecules to determine the expression of specific genes and closely regulated by various signaling molecules in macrophages. The transcriptional regulation of macrophage polarization has been the focus of numerous recent studies. For example, STAT1, C/EBP- $\alpha, \mathrm{C} / \mathrm{EBP}-\delta$, IRF9, KLF6, and NF- $\kappa B$ are important transcription factors involved in polarization of M1 macrophage, whereas PPARs, STAT3, STAT6, C/EBP- $\beta$, IRF4, KLF4, GATA3, and c-MYC are associated with M2 macrophage polarization (21-24).

Transcription factors control the transcription rates to regulate the amounts of gene products, but transcription factors themselves are also regulated. There are several ways that the activities of transcription factors are regulated. Like all proteins, transcription factors are transcribed from a gene to RNA, which is then translated into protein. Any of these steps involving transcription and translation can be regulated to affect the production of transcription factors. Many transcription factors are located in the cytoplasm before activation and undergo nuclear translocation in response to the appropriate signals, such as NF- $\kappa B$ that must translocate to the nucleus before activating target gene transcription (25). Some transcription factors, such as STAT proteins, must be phosphorylated before they can bind DNA (26). A few of transcription factors should interact with other transcription factors before activated, for example, LXR and RXR must form heterodimer before binding to specific DNA sequences called LXR-responsive elements in the target genes (27).

MicroRNAs (miRNAs) are endogenous small (20-22 nucleotides long) non-coding RNAs that induce inhibition of target gene expression within metazoan cells by binding to direct complementary sequences in the $3^{\prime}$ untranslated region ( $\left.3^{\prime} \mathrm{UTR}\right)$ of mRNAs to target them for translational repression or degradation (28). miRNA regulation is characterized by its active participation in and strict control of the negative feedback loop to confer significant influences on a biological pathway (29). The roles of miRNAs in the regulation of macrophage polarization are largely unknown, and only several miRNAs are known to be involved in the regulation of macrophage polarization (30). Recent studies have shown that some miRNAs participate in macrophage polarization by regulating transcription factors. Hence, in this review, we focused on recent progress regarding the crucial roles of miRNAs in the regulation of macrophage polarization via modulating transcription factors (Figure 1; Table 1) and tried to provide a better understanding of the biological functions of miRNAs in macrophage polarization.

\section{miRNAs REGULATE MACROPHAGE POLARIZATION THROUGH TRANSCRIPTION FACTORS}

\section{Peroxisome Proliferator-Activated Receptors}

Peroxisome proliferator-activated receptors are a group of transcriptional factors belonging to the ligand-activated nuclear hormone receptor superfamily, including PPAR- $\alpha, \operatorname{PPAR}-\delta$, and PPAR- $\gamma(21,31)$. PPARs have been shown to transcriptionally regulate the activation of macrophages in health and disease states, including cardiovascular disease, obesity, insulin resistance, and Chagas' disease $(31,32)$. Penas et al. showed that PPAR- $\alpha$ ameliorates macrophage inflammatory responses and regulates the changes of the phenotype of peritoneal macrophages isolated from $T$. cruzi-infected mice (31). PPAR- $\alpha$ induces M2 macrophage polarization and enhances the expression of M2 markers (Arg-1, YM-1, Mrc1, and TGF- $\beta$ ) through inhibiting the expression of nitric oxide synthase 2 (NOS2) and pro-inflammatory cytokines in T. cruzi-infected mice (31). Kang et al. found that the deletion of the myeloid PPAR- $\delta$ gene results in adipocyte dysfunction, insulin resistance, and hepatosteatosis (33). IL-13 can upregulate the expression of PPAR- $\delta$ to induce the polarization of adipose tissue-resident macrophages toward the alternatively activated. Also, myeloid-specific PPAR- $\delta^{-1-}$ mice fed high-fat diet (HFD) showed increased M1 and decreased M2 markers in white adipose tissue and liver (33). PPAR- $\gamma$ expression levels were positively correlated with the expression of M2 markers (Mrc1, AMAC1, and IL-10) in human carotid atherosclerotic lesions (34). Furthermore, PPAR- $\gamma$ controls the inflammatory response by negatively interfering with pro-inflammatory signaling pathways, such as AP-1, NF- $\kappa \mathrm{B}$, or STAT3 in activated M1 macrophages (34).

The important roles of miR-9 in innate immune and antiinflammatory response have been described $(35,36)$. miR- 9 


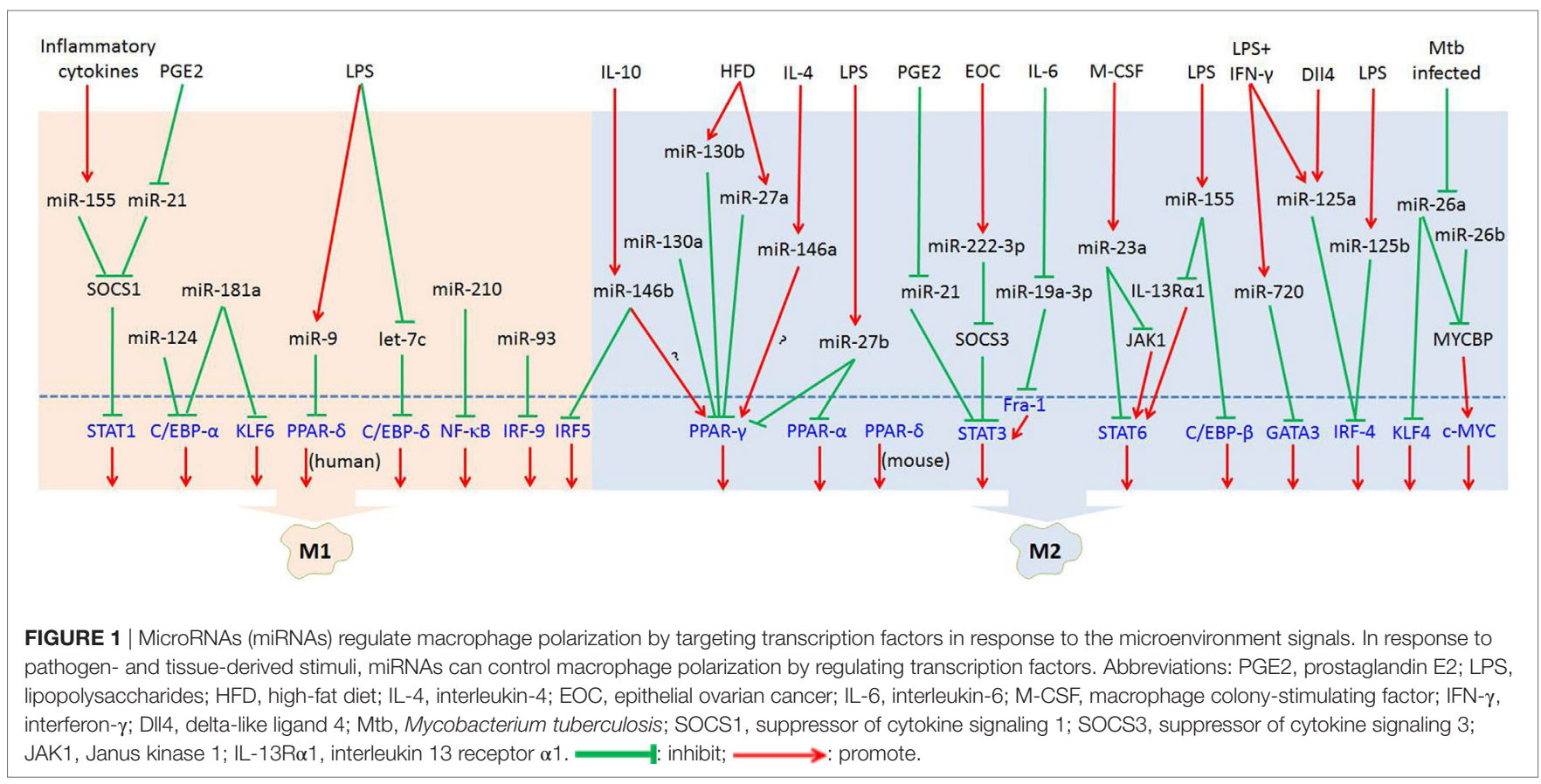

TABLE 1 | MicroRNAs (miRNAs) control macrophage polarization by regulating transcription factors.

\begin{tabular}{|c|c|c|c|c|c|c|}
\hline miRNAs & Targets & Pathways & Function & Cell types & $\begin{array}{l}\text { Regulation of macrophage } \\
\text { phenotype }\end{array}$ & Reference \\
\hline miR-9 & PPAR- $\delta$ & Directly & Suppresses inflammatory responses & PBMCs, HEK293 & Suppresses M1 & (37) \\
\hline \multirow[t]{2}{*}{ miR-27b } & PPAR- $\gamma$ & Directly & Promotes inflammatory responses & THP-1, PBMCs & Promotes M1, suppresses M2 & (43) \\
\hline & PPAR- $\alpha$ & Directly & Promotes inflammatory responses & HuH7, HepG2 & Promotes M1, suppresses M2 & (44) \\
\hline miR-130a & PPAR- $\gamma$ & Directly & Promotes inflammatory responses & THP-1 & Promotes M1, suppresses M2 & (45) \\
\hline miR-130b & PPAR- $\gamma$ & Directly & Promotes inflammatory responses & Peritoneal macrophages (PMs) & Promotes M1, suppresses M2 & (46) \\
\hline $\mathrm{miR}-146 \mathrm{~b}$ & IRF5 & Directly & Suppresses inflammatory responses & BMDMs & Suppresses M1, promotes M2 & $(100)$ \\
\hline \multirow[t]{3}{*}{ miR-155 } & SOCS1 & STAT1 & Promotes inflammatory responses & PBMCs, microglia, and HRPE & Promotes M1 & $(62,63)$ \\
\hline & $\| \mathrm{IL}-13 \mathrm{R} \alpha 1$ & STAT6 & Promotes inflammatory responses & THP-1, PBMCs, and HeLa & Suppresses M2 & $(61,64)$ \\
\hline & C/EBP- $\beta$ & Directly & Suppresses tumor progression and metastasis & $\begin{array}{l}\text { SK-Hep-1, HepG2, HeLa, } \\
\text { THP-1, U251, and 95D }\end{array}$ & Suppresses M2 & $(84)$ \\
\hline miR-21 & STAT3 & Directly & Promotes inflammatory responses & PMs & Suppresses M2 & (66) \\
\hline miR-23a & JAK1 & STAT6 & Suppresses tumor progression and metastasis & RAW264.7, PMs, and BMDMs & Suppresses M2 & (71) \\
\hline miR-124 & C/EBP- $\alpha$ & Directly & Suppresses inflammatory responses & BMDMs, microglia & Suppresses M1, promotes M2 & $(81,82)$ \\
\hline \multirow[t]{2}{*}{ miR-181a } & $\mathrm{C} / \mathrm{EBP}-\alpha$ & Directly & Promotes tumor progression and metastasis & $\begin{array}{l}\text { THP-1, RAW264.7, MCF-7, } \\
\text { OVCAR3, and HCT116 }\end{array}$ & Suppresses M1, promotes M2 & (83) \\
\hline & KLF6 & Directly & Promotes tumor progression and metastasis & $\begin{array}{l}\text { THP-1, RAW264.7, MCF-7, } \\
\text { OVCAR3, and HCT116 }\end{array}$ & Suppresses M1, promotes M2 & (83) \\
\hline let-7c & $\mathrm{C} / \mathrm{EBP}-\delta$ & Directly & Suppresses inflammatory responses & GM-BMM, M-BMM & Suppresses M1, promotes M2 & (86) \\
\hline miR-125a & IRF4 & Directly & Suppresses tumor progression and metastasis & BMDMs & Promotes M1, suppresses M2 & (98) \\
\hline miR-125b & IRF4 & Directly & Suppresses tumor progression and metastasis & 293T, RAW264.7, and BMMs & Promotes M1, suppresses M2 & (99) \\
\hline miR-93 & IRF9 & IRG1 & Suppresses inflammatory responses & BMDMs & Suppresses M1, promotes M2 & (96) \\
\hline miR-26a & $\begin{array}{l}\text { KLF4 } \\
\text { MYCBP }\end{array}$ & $\begin{array}{l}\text { Directly } \\
\text { C-MYC }\end{array}$ & $\begin{array}{l}\text { Promotes inflammatory responses } \\
\text { Suppresses tumor progression and metastasis }\end{array}$ & $\begin{array}{l}\text { RAW264.7, HEK293, EC109, } \\
\text { KYSE450, and KYSE150 }\end{array}$ & $\begin{array}{l}\text { Promotes M1, suppresses M2 } \\
\text { Suppresses M2 }\end{array}$ & $\begin{array}{c}(104) \\
(111,113)\end{array}$ \\
\hline
\end{tabular}

?, uncertain 
overexpression was reported to inhibit inflammation in rat mesenteric lymphatic endothelial cells (35). Recently, miR-9 was found to regulate PPAR- $\delta$ expression in human monocytes during the inflammatory response (37). It is believed that PPAR- $\delta$ can induce a phenotype switch from M1 to M2 macrophages in mice. However, Bouhlel et al. showed that activation of PPAR- $\delta$ does not promote human monocyte differentiation into antiinflammatory M2 macrophages (38). In addition, Thulin et al. demonstrated that activation of PPAR- $\delta$ is of importance in M1 pro-inflammatory macrophages in humans (37). These studies may reflect differences between mouse and human macrophages in terms of the function of PPAR- $\delta$. Bioinformatic analysis revealed that miR-9 can specifically bind to the $3^{\prime} \mathrm{UTR}$ of the PPAR- $\delta$ using a luciferase reporter construct. The expression of PPAR- $\delta$ mRNA is also suppressed by miR-9 in monocytes after treatment with pro-inflammatory agent LPS. Furthermore, inhibition of miR-9 was found to upregulate the mRNA expression of PPAR- $\delta$ in human primary monocytes (37). Thus, these results suggest that miR-9 inhibits macrophage inflammatory response via modulating the expression of PPAR- $\delta$.

The miR-27 family is composed of two isoforms, miR-27a and miR-27b. Several studies demonstrated that miR-27 plays an important role in inflammation-related diseases, such as atherosclerosis and obesity (39-42). A recent study by Yao et al. revealed that miR-27a triggers an inflammatory response via promoting M1 macrophage polarization in obesity-induced insulin resistance in mice (40). They demonstrated that upregulation of miR-27a could suppress the expression of PPAR- $\gamma$ with M1 polarization and increase the expression of $\mathrm{p}-\mathrm{NF}-\mathrm{\kappa B}$ with degradation of I $\mathrm{B} \alpha$ in mice fed HFD. Jennewein et al. showed that the M1 activator LPS upregulates miR-27b to decrease the expression of PPAR- $\gamma$ in M1 macrophages. Furthermore, inhibition of miR-27b impairs the ability of LPS to reduce the PPAR- $\gamma$ mRNA half-life (43). Overexpression and inhibition of miR-27b in HuH7 cells significantly decreased and increased the PPAR- $\alpha$ levels, respectively (44). Thus, PPAR- $\alpha$ may be another transcription factor regulated by miR-27b, which is involved in the regulation of macrophage polarization. Taken together, miR-27 may serve as a crucial molecular regulator in the transcriptional regulation of macrophage polarization and may also be a potential therapeutic target for inflammatory diseases.

Low expression of miR-130a is closely associated with the progression and metastasis of non-small cell lung cancer (NSCLC) (45). It was found that miR-130a expression is inversely correlated with PPAR- $\gamma$ and CD163 in NSCLC tissues. Furthermore, the expression level of miR-130a in M1 macrophage was much higher than that in M2 macrophages. Also, the flow cytometric analysis showed that transfection of macrophages with miR-130a mimic significantly enhanced the expression of CD80, iNOS, and TNF- $\alpha$ (M1 marker) in M1 macrophages but suppressed the expression of CD206, IL-10, and CCL22 (M2 marker) in M2 macrophages. Since the bioinformatic analysis demonstrated that PPAR- $\gamma$ is a potential target of miR-130a, miR-130a may be involved in the regulation of macrophage polarization via modulating PPAR- $\gamma$ (45). In the further study to elucidate the molecular mechanism of miR-130a involvement in the regulation of macrophage polarization, Lin et al. demonstrated that
miR-130a skews polarization of human monocyte-derived macrophages from an M2 toward an M1 phenotype through targeting PPAR- $\gamma$ 3'UTR for repression (45). In addition to miR-130a, miR-130b was found to promote adipose tissue inflammation and insulin resistance in diabetic mice via regulating macrophage polarization (46). Similar to the molecular mechanism of miR130a-mediated M1/M2 macrophage polarization, miR-130b also skews their polarization toward an M1 phenotype via repression of PPAR- $\gamma$ (46).

The miR-146 family comprises miR-146a and miR-146b, which promote tumor growth as well as exert a pro-inflammatory role in many diseases, such as Alzheimer, acute lung injury, coronary artery disease, and the impairment of diabetic wound healing (47-51). miR-146a/b has also been identified as negative regulators of TLR4 signaling $(48,52)$. TLR4 signaling plays an essential role in the regulation of M1 macrophage polarization. Also, Huang et al. found that miR-146a can enhance the activation of PPAR- $\gamma$ to promote M2 macrophage polarization. The authors also demonstrated that overexpression of miR-146a significantly increases the expression of PPAR- $\gamma$, whereas interference of miR146a decreases its expression at both protein and mRNA levels (53). Although PPAR- $\gamma$ was involved in the miR-146a-mediated M2 macrophage polarization, the specific mechanism underlying miR-146a regulation of PPAR- $\gamma$ remains unknown. Further research will be needed to explain how miR-146a works through PPAR- $\gamma$ to regulate macrophage polarization. Besides miR146a, miR-146b can significantly increase the expression of the transcription factor PPAR- $\gamma$ (54), suggesting that miR-146b may enhance the activation of M2 macrophage via promoting PPAR- $\gamma$ expression.

\section{Signal Transducers and Activators of Transcription}

The members of the STAT protein family are the key transcription factors that mediate macrophage M1/M2 polarization. It has been demonstrated that activation of STAT1 promotes an inflammatory response in various diseases, such as atherosclerosis and inflammatory bowel disease $(55,56)$. STAT1 is the important mediator of M1 macrophage polarization induced by IFN- $\gamma$, which can be derived from innate lymphocytes or Th1 cells (22). IFN- $\gamma$ ligand binding to its receptor induces Janus kinase 1/2-mediated tyrosine phosphorylation and subsequent dimerization of STAT1, which binds as a homodimer to cis elements known as IFN- $\boldsymbol{\gamma}$ activated sites in the promoter of target M1 signature genes [e.g., NOS2, IL-12, and class II transactivator (CIITA)] (22). Activation of STAT3 plays a crucial role in the progression of human epithelial ovarian cancer by regulating macrophage polarization in the tumor microenvironment (57). IL-10 and IL-6 induce STAT3-mediated expression of genes (IL-10, TGF- $\beta 1$, and Mrc1) associated with an M2-like phenotype. It has been reported that STAT6 $^{-1-}$ eosinophils are unable to migrate to the lung during allergic airway inflammation (58). STAT6 is the key transcription factor in IL-4- or IL-13-mediated M2 macrophage polarization. STAT6 was found to activate transcription of genes typical of M2 polarization, such as Mrc1, Retnl $\alpha$, Fizz1, Chi313, and Ym1 (8). Also, STAT-mediated activation of macrophages is modulated by 
members of the SOCS family. For instance, IFN- $\gamma$ stimulation upregulates suppressor of cytokine signaling 1 (SOCS1) and suppressor of cytokine signaling 3 (SOCS3), and, in turn, inhibit the action of STAT1 and STAT3, respectively $(8,59)$.

miR-155 is a multi-functional miRNA known to play diverse roles in inflammation and immunity. For instance, miR-155 promotes M1 macrophage polarization and exerts an antibacterial role in macrophages from $\mathrm{Akt}^{-/-}$mice (60). miR-155 is also a crucial molecule for the fine-tuning of allergic disease and asthma (61). Xu et al. revealed a key role for the miR-155/SOCS1 axis in defining PI3-K/Akt1-mediated M1 skewing in vitro and in vivo (60). Another study by Moore et al. showed that miR-155 mimic can significantly increase both pro-inflammatory cytokine and surface molecule expression by decreasing the expression of SOCS1 (62). Furthermore, Kutty et al. showed that the increase in miR-155 expression by the inflammatory cytokines was associated with an increase in STAT1 activation, as well as an increase in protein binding to putative STAT1 binding elements present in the miR-155 gene promoter region (63). Given that SOCS1 is a negative regulator of STAT1 in the regulation of M2 macrophage polarization. These findings suggest that the role of miR-155 in macrophage polarization is through regulation of the SOCS1/ STAT1 pathway. In addition, Martinez-Nunez et al. demonstrated that miR-155 directly targets interleukin 13 receptor $\alpha 1$ (IL-13R $\alpha 1$ ) and decreases the levels of IL-13R $\alpha 1$ protein, resulting in decreased activation of STAT6 in human macrophages (61). By targeting IL-13R $\alpha 1$ and regulating the STAT6 cascade, miR-155 may trigger pro-inflammatory immune responses in asthma and allergic disease (61). What is more, silencing miR-155 has a suppressive role in M1 macrophage polarization and drives macrophage polarization toward the M2 phenotype by increasing the phosphorylation of STAT6 (64).

It was reported that miR-21 induces inflammatory responses in macrophages by binding to murine TLR7 and human TLR8, and then triggers a TLR-mediated prometastatic inflammatory response, likely leading to tumor growth and metastasis (65). More recently, miR-21 was found to play a vital role in driving M1 and inhibiting M2 peritoneal macrophage polarization. Wang et al. showed that the M1 markers, such as TNF- $\alpha$, IL-6, IL-1 $\beta$, and IL-12p40, were either not expressed or expressed at lower levels, whereas M2 markers, such as IL-10, RETNL- $\alpha$, Arg-1, and Chi3 13 were elevated in miR-21 $1^{-1-}$ macrophages when compared with those in wild-type (WT) macrophages (66). The authors also demonstrated that miR-21 can control macrophage polarization via regulating the expression of STAT3 and SOCS1. miR-21 mimic inhibited STAT3 and SOCS1 expression while the antagomir enhanced STAT3 and SOCS1 expression in WT macrophages. Furthermore, the miR-21 mimic can directly target STAT3 3'UTR sequences (66). However, some studies showed that miR-21 inhibits the pro-inflammatory macrophage polarization and enhances the anti-inflammatory macrophage phenotype in other macrophage cell lines $(67,68)$. These discrepancies may be due to the fact that miR-21 might exert different effects on macrophage polarization depending on cell types and in vivo microenvironment.

A recent report by Xiang et al. demonstrated that miR-222-3p promotes M2 macrophage polarization in vitro and in vivo, which can facilitate the progression and metastasis of epithelial ovarian cancer (69). The authors showed that miR-222-3p can suppress the expression of SOCS3 via targeting its $3^{\prime} \mathrm{UTR}$. SOCS3 has been identified as a negative regulator of STAT3 in controlling M1 macrophage polarization. Furthermore, the STAT3 pathway was either activated or inhibited when transfected with the miR222-3p mimic and the inhibitor in macrophages, respectively (69). Thus, these data suggest that miR-222-3p plays an important role in the polarization of tumor-promoting M2 macrophages by modulating the SOCS3/STAT3 pathway.

miR-19a-3p was reported to suppress the growth and metastasis of breast tumor by inhibiting macrophage skew to M2 phenotype via downregulating Fra-1 (70). Further study showed that transfection with miR-19a-3p mimic or inhibitor results in inhibition or stimulation of the expressions of the Fra-1 downstream genes pSTAT3 and STAT3, respectively (70). These studies suggest that miR-19a-3p plays an important role in the regulation of macrophage polarization by regulating the expression of the Fra-1/STAT3 pathway.

Recently, Ma et al. found that miR-23a exerts an anti-tumor effect by inhibiting M2 macrophage polarization (71). The underlying mechanism is that STAT6 occupies the miR-23a promoter and activates its transcription in IL-4-stimulated macrophages. Then, miR-23a, in turn, inhibits the Janus kinase 1 (JAK1)/STAT6 pathway and reduces the production of M2 phenotype cytokines by directly targeting JAK1 and STAT6 (71). Notably, STAT3, but not STAT1, also binds to the miR-23a cluster promoter, suggesting that STAT3 may be involved in the miR-23a-mediated inhibition of M2 macrophage polarization (71).

\section{CCAAT-Enhancer-Binding Proteins}

The C/EBP family, a member of bZIP (basic region leucine zipper) transcription factors, plays crucial roles in myeloid development and macrophage activation (22). Previous studies have shown that transcriptional factors $\mathrm{C} / \mathrm{EBP}-\alpha$ and $\mathrm{C} / \mathrm{EBP}-\delta$ participate in TLR-induced M1 activation, whereas C/EBP- $\beta$ is involved in the polarization of macrophages to the $\mathrm{M} 2$ phenotype (72-74). Macrophage-specific deficiency of C/EBP- $\alpha$ can protect against high-fat-induced inflammation in skeletal muscle (73). $\mathrm{C} / \mathrm{EBP}-\alpha$ also acts as a tumor suppressor in the development of various cancers, including pancreatic cancer, lung cancer, acute myeloid leukemia and head and neck squamous cell carcinoma (75-78). It has been shown that C/EBP $\beta$ involves various biological functions, including a role in adipocyte differentiation, tumor progression, inflammation, and immune function $(72,79)$. C/ EBP- $\delta$ has been shown to play a key role in adipocyte differentiation and inflammation $(72,80)$. More recently, the concerns have been raised about the roles of four miRs including miR-124, miR181a, miR-155, and let-7c in regulating C/EBP in macrophage polarization.

Microglia is one of the inflammatory cells in the central nervous system (CNS), which plays a diverse role via polarizing into two main states, namely, classically activated M1 and alternatively activated M2 (81). Brain-specific miR-124 is expressed in microglia in the normal CNS and during experimental autoimmune encephalomyelitis (EAE). In vivo administration of miR-124 ameliorates both EAE symptoms and inflammation by 
affecting macrophages in the CNS (82). Also, the expression of miR-124 is inversely related to the activation state of microglia and macrophages in the CNS. High levels of C/EBP- $\alpha$ expression are associated with the activated $\mathrm{CD} 45^{\text {high }}$ microglia. Intriguingly, transfection of macrophages with miR-124 was reported to downregulate both $\mathrm{C} / \mathrm{EBP}-\alpha$ and $\mathrm{CD} 45$, suggesting that the decrease in C/EBP- $\alpha$ corresponds to the CD $45^{\text {low }}$ phenotype of macrophages. Moreover, transfection of macrophages with miR-124 also results in downregulation of markers and cytokines associated with pro-inflammatory M1 macrophage phenotype, including CD86, MHC class II, TNF- $\alpha$, and NOS2, but the upregulation of cytokines and markers associated with anti-inflammatory M2 macrophage phenotype, including TGF- $\beta 1$, Arg- 1 , and FIZZ1. Further study demonstrated that miR-124 controls these markers and cytokines of macrophage activation by directly suppressing the transcription factor C/EBP- $\alpha$ and its downstream target PU.1 (82). In addition, Yu et al. demonstrated that miR-124 promotes microglia $\mathrm{M} 2$ polarization and attenuates inflammatory response by directly targeting the $3^{\prime} \mathrm{UTR}$ of $\mathrm{C} / \mathrm{EBP}-\alpha$ for repression in intracerebral hemorrhage (81).

Besides miR-124, miR-181a is also a pivotal molecule regulating M2 mediated tumor cell migration, invasion and metastasis by targeting C/EBP- $\alpha$. miR-181a is a negative regulator of M1 macrophage phenotype, which overexpression augments M2 activation and drives a transition from an M1 toward an M2 phenotype. Furthermore, luciferase assay showed that miR-181a can significantly inhibit $\mathrm{C} / \mathrm{EBP}-\alpha$ translation by targeting the $3^{\prime} \mathrm{UTR}$ of C/EBP- $\alpha$ mRNA. In addition, overexpression of miR181a inhibits C/EBP- $\alpha$ protein expression (83), suggesting that miR-181a is also an important regulator of transcriptional factor $\mathrm{C} / \mathrm{EBP}-\alpha$ in macrophage polarization.

It has been shown that TAMs exhibit an M2 phenotype and are known to promote tumor proliferation. C/EBP- $\beta$ is highly expressed in TAMs both in vitro and human tumors in situ. In human solid tumors, the expression of $\mathrm{C} / \mathrm{EBP}-\beta$ protein is inversely correlated with miR-155 expression (84). Akt2 ablation can result in a decrease in miR-155 levels and an increase in C/ EBP- $\beta$ expression (85). Further studies have demonstrated that $\mathrm{C} / \mathrm{EBP}-\beta$ is a direct target gene of miR-155. Induction of miR155 significantly decreases the cytokine production in TAMs via inhibiting the expression of C/EBP- $\beta$ at both $\mathrm{mRNA}$ and protein levels (84). These data suggest that miR-155 may promote the M1 polarization of macrophages via inhibiting C/EBP- $\beta$ signaling cascade. Previous studies have demonstrated that miR-155 promotes M1 macrophage polarization through regulating STAT6 (61), suggesting that miR-155 regulates macrophage polarization by modulating different transcription factors.

In alveolar macrophages from fibrotic mouse lungs exhibiting an M2 phenotype, let-7c is upregulated when compared with those from normal mouse lungs (86-89). Overexpression of let7c in GM-BMM (M1 macrophages) diminishes M1 phenotypic expression, while promotes macrophage polarization toward the M2 phenotype (86). These studies suggest that let-7c may be involved in pulmonary fibrosis via regulating alveolar macrophage polarization. Moreover, $\mathrm{C} / \mathrm{EBP}-\delta$ acts as an amplifier of NF- $\kappa \mathrm{B}$ response, which is necessary for persistent TLR4-induced inflammatory signals (74). Banerjee et al. found that let-7c plays a crucial role in the regulation of macrophage polarization through directly targeting C/EBP- $\delta$ (86). However, C/EBP- $\delta$ may not be the only mediator for let-7c in the regulation of the macrophage polarization, because knockdown of $\mathrm{C} / \mathrm{EBP}-\delta$ does not duplicate all of the effects of let-7c in macrophages (86). Thus, there may be other transcription factors or cytokines to mediate let-7c effects on macrophage polarization.

\section{Interferon Regulatory Factors}

Interferon regulatory factors were originally described as the regulators of type I IFN expression and signaling and also identified as important mediators of macrophage polarization. Several their family members have been reported in association with a specific phenotype $(22,90)$. IRF4 can be induced by IL-4 via jumonji domain-containing protein (JMJD) 3, which is important for the induction of M2 macrophage responses to helminth infection $(91,92)$. Also, IL-4 regulates a subset of genes associated with the M2 phenotype, including several MHC-II genes, CIITA, cytochrome P450 1B1 (CYP1B1), and IL-1 receptor antagonist gene (IL1RN), which were dysregulated in IRF4-deficient macrophages (91). IRF5 plays a significant role in regulating the polarization of adipose tissue macrophages and insulin resistance during obesity (93). LPS-induced recruitment of IRF5 promotes M1 macrophage polarization via equipping the cells with an IL- $12^{\text {high }}$ IL-23 $3^{\text {high }}$ IL- $10^{\text {low }}$ cytokine profile (94). It has been shown that the absence of IRF9 results in profound protection from dextran sodium sulfate-induced colon inflammation (95). IRF9 is known to regulate type I interferon signaling and also plays a role in promoting M1 macrophage polarization $(21,96)$.

Notch signaling has been identified as an evolutionarily conserved pathway to modulate the M1/M2 polarization of macrophages. It has been reported that differentiation of TAMs depends on the transcriptional regulator of Notch signaling in a mouse mammary tumor model (97). Macrophages overexpressing miR-125a have an enhanced phagocytic activity and an inhibitory effect on tumor growth by remodeling the immune microenvironment (98). miR-125a is a downstream molecule of Notch signaling with a crucial role in promoting $\mathrm{M} 1$ and inhibiting M2 polarization (98). IRF4 is an important transcription factor involved in this pathway. It was found that the expression of the IRF4 protein is was markedly decreased in BMDMs transfected with miR-125a. The reporter assay showed that miR-125a reduces luciferase activity in cells transfected with reporters containing the WT 3'UTR of IRF4, which is abrogated by disruption of the proximal seed sequence (302-309 bp) in the unique seed sequence in the IRF4 3'UTR (98). Further study showed that miR-125a upregulates the M1 markers iNOS, IL-12, and TNF- $\alpha$ and downregulates the M2 marker mannose receptor (Mrc1) in BMDMs. IRF4 knockdown reduces Mrcl expression and nearly reverses miR-125a ASO-mediated Mrcl upregulation (98). These data suggest that miR-125a inhibits M2 macrophage polarization and enhances pro-inflammatory macrophage activation by targeting IRF4. Moreover, miR-125b is involved in the regulation of macrophage activation by targeting IRF4. Overexpression of miR-125b significantly enhances surface expression of costimulatory molecules and increases macrophage response to IFN- $\gamma$ by inhibiting the expression IRF4 (99). 
A recent study by Peng et al. showed that miR-146b strikingly inhibits M1 macrophage polarization and ameliorates the development of colitis (100). Furthermore, the expression of IRF5 was decreased in the mucosa of the colon with the treatment of miR-146b mimic. Luciferase assays demonstrated that human IRF5 is a direct target of miR-146b. Moreover, the miR-146b mimic markedly decreased the expression of IRF5 at both protein and mRNA levels in IFN- $\gamma / \mathrm{LPS}$-induced M1 macrophages. Also, IRF5 overexpression rescued miR-146b mimic-induced inhibition of M1 macrophage polarization (100). Therefore, miR-146b inhibits M1 macrophage polarization by directly targeting IRF5.

Macrophage polarization plays a crucial role in the modulation of an angiogenesis in distal ischemic muscle. Ganta et al. demonstrated that overexpression of miR-93 induces M2-likepolarization in macrophages to promote angiogenesis (96). miR-93 modulates the expression of the immune responsive gene (IRG) 1 to promote M2 macrophage polarization. However, IRG1 is not a direct target of miR-93. Reporter assays confirmed IRF9 as a direct target of miR-93. Also, overexpression of IRF9 significantly induces IRG1-expression in macrophages (96). These data suggest that miR-93 reduces the expression of IRG1 by targeting IRF9, leading to the polarization of M2 macrophages.

\section{Kruppel-Like Factors}

Kruppel-like factors are a subfamily of the zinc finger class of DNA-binding transcriptional regulators. Several family members of KLFs, such as KLF4 and KLF6, have been reported to play important roles in the regulation of macrophage polarization. Liao et al. found that deficiency of myeloid KLF4 results in increased pro-inflammatory cytokines in the skin and a delay in wound healing (15). KLF4 was found to cooperate with STAT6 to induce an M2 genetic program and inhibit M1 targets via sequestration of coactivators required for NF- $\mathrm{BB}$ activation (15). Goodman et al. observed that myeloid-specific deficiency of KLF6 diminishes the expression of dextran sulfate sodium-induced pro-inflammatory cytokine genes and enhances the expression of anti-inflammatory genes in colon tissues (101). KLF6 was found to promote M1 phenotype through cooperation with NF- $\kappa \mathrm{B}$ and inhibit the M2 targets by suppressing the expression of PPAR- $\gamma$ (102).

It is generally accepted that Mycobacterium tuberculosis (Mtb) interferes with M1 polarization and induces the M2 profile (103). Sahu et al. found that KLF4 upregulates Mcl-1 expression thereby repressing autophagy during Mtb infection. Furthermore, silencing of KLF4 represses arginase activity while augmenting nitrite production and the expression of iNOS during Mtb infection (104). miR-26a was validated as a negative regulator of the expression of KLF4 in Mtb-infected macrophages. The role of miR-26a in transcriptional regulation of the iNOS/arginase balance was further strengthened (104). Therefore, the miR-26a/KLF4 signaling axis is a determinant of the M1/M2 macrophage phenotype during Mtb infection. In addition, KLF6 was validated as a potential target of miR-181a. Bi et al. demonstrated that miR-181a promotes M2 macrophage polarization via directly targeting KLF6 (83).

\section{GATA Binding Protein 3}

GATA binding protein 3 belongs to the GATA family of transcription factors, which are involved in the regulation of M2 macrophage polarization. GATA3 is significantly elevated in M2 macrophages. Treatment of mouse monocytic cell line with GATA3 shRNA markedly decreases the expression of M2 markers (24).

Zhong and Yi found that miR-720 inhibits breast cancer metastasis through regulating macrophage polarization in the tumor microenvironment (105). Overexpression of miR-720 inhibits the expression of genes associated with M2 phenotypes, such as CD163, IL-10, and CCL17, but has no effect on the expression of M1 marker CD86 and little effect on the production of M1 macrophage cytokines, TNF- $\alpha$ and IL-6 (105). These results suggest that miR-720 is important for the polarization of macrophage toward an M2 phenotype. Furthermore, the authors also revealed that GATA3 is a potential target of miR-720 involved in M2 polarization. Luciferase reporter assay revealed that GATA3 is regulated by miR-720 via direct binding to its $3^{\prime} \mathrm{UTR}$. Also, overexpression of miR-720 results in downregulation of GATA3 expression at both mRNA and protein levels in THP-1 cells (105). Notably, GATA3 that is regulated by miR-720 inhibits M2 polarization since ectopic expression of GATA3 restores the expression of M2 marker CD163 in miR-720-overexpressed THP-1 cells. However, ectopic expression of GATA3 only partially restores the expression of other genes associated with M2 phenotypes, such as IL-10, CCL17, and Arg-1, suggesting that other downstream targets of miR-720 may also contribute to miR-720-regulated M2 polarization (105). Taken together, GATA3 is one of the miR-720 downstream targets and, at least partially, mediates the inhibitory effects of miR-720 on M2 macrophage polarization.

\section{Nuclear Transcription Factor-кB}

In mammals, the NF- $\kappa \mathrm{B}$ family of transcription factors comprises five members: RelA (p65), RelB, c-Rel, NF-kB1 (p105/

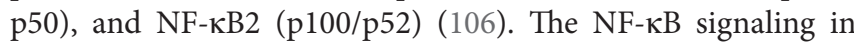
numerous cell types is closely related to the development of metabolic diseases and inflammatory diseases (107). NF- $\mathrm{BB}$ is a critical transcriptional regulator of M1 macrophage polarization induced by TLR4. TLR4 signaling activates Iא-B kinase (IKK) to phosphorylate Iк-B via myeloid differentiation primary response gene 88 (MyD88)-dependent and MyD88-independent [TIR domain-containing adapter-inducing IFN- $\beta$ (TRIF)-dependent]

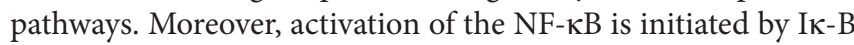
phosphorylation in response to microenvironmental stimuli. After the phosphorylation of I $\mathrm{K}-\mathrm{B}$ and subsequent degradation, $\mathrm{NF}-\kappa \mathrm{B}$ translocates to the nucleus and controls the expression of various target genes by binding to specific DNA sequences (107, 108). Activation of NF- $\kappa$ B promotes M1 macrophage polarization by regulating the expression of pro-inflammatory cytokines.

miR-210 plays an important role in both inflammation and immunity. It inhibits pro-inflammatory cytokine expression and the NF- $\kappa \mathrm{B}$ pathway in osteoarthritis (109). Qi et al. found that miR-210 functions as a negative regulator of LPS/TLR4 signaling (110). Overexpression of miR-210 suppresses the TLR4-induced expression of pro-inflammatory cytokines TNF- $\alpha$ and IL-6 via targeting NF- $\mathrm{\kappa B}$ in macrophages. Furthermore, the miR-210 mimic can inhibit NF- $\kappa \mathrm{B}$ activation by targeting molecules downstream of IKK- $\beta$ in LPS-stimulated macrophages. In addition, Zhang and his colleagues found that miR-210 mimic 
suppresses the activation of NF- $\kappa \mathrm{B}$ via increasing the I $\kappa-\mathrm{B} \alpha$ level and reducing the p65 expression in LPS-treated cells (109). These data suggest that miR-210 acts as a key regulator to inhibit M1 macrophage polarization, which may provide a therapeutic target for inflammatory diseases.

\section{C-MYC}

c-MYC is a critical transcription factor in the regulation of alternative macrophage activation and TAM biology $(111,112)$. It acts as a transcriptional activator to regulate the expression of target genes by binding to enhancer box sequences (E-boxes) in the promoter region. It has been confirmed that c-MYC can directly regulate a significant set of M2-associated gene expression (ALOX15, Mrc1, and SCARB1). Also, c-MYC promotes M2 macrophage polarization by upregulating the IL-4 signaling mediators STAT6 and PPAR- $\gamma$ (111).

miR-26 family, including miR-26a and miR-26b, was reported to be closely linked to the pathogenesis of esophageal squamous cell carcinoma (ESCC). Li et al. showed that miR$26 \mathrm{a}$ and miR-26b expression was significantly decreased in the majority of ESCC tissues (113). Both miR-26a and -26b inhibit ESCC cell proliferation via directly targeting the MYC binding protein (MYCBP) 3'UTRs for repression. MYCBP binds to the $\mathrm{N}$-terminal region of $\mathrm{c}-\mathrm{MYC}$ and enhances its ability to activate E box-dependent transcription. Moreover, upregulation of miR$26 \mathrm{a}$ and $-26 \mathrm{~b}$ results in a decreased expression of most c-MYC target genes, suggesting that miR-26 family can inhibit ESCC cell proliferation via suppression of MYCBP and subsequent inhibition of the c-MYC pathway (113). It is well received that TAMs play a crucial role in tumor growth, invasion, angiogenesis, and metastasis formation. Given that c-MYC is a key transcription factor in the regulation of TAM biology, miR-26 family members may act as tumor suppressors by suppressing the c-MYC pathway and decrease TAMs in ESCC tissues.

\section{CONCLUSION}

During the past few years, significant progress has been made to unravel how transcription factors define macrophage identity and control macrophage polarization during homeostasis or in challenging situations (23). Recently, miRNAs have been found to act as upstream regulators of transcription factors involved in the regulation of macrophage polarization (PPARs, STATs, C/ EBP, IRFs, KLFs, GATA3, NF- $\kappa \mathrm{B}$, and c-MYC). The biological role of miRNA-transcription factor networks for macrophage polarization involves the development of multiple diseases. An outline of the role of miRNAs in the transcriptional regulation of macrophage polarization provides insights into their regulation of inflammation, immune response and tumor. However, the mechanism for miRNAs to regulate macrophage polarization via transcription factors appears complicated. For example, Wang et al. demonstrated that miR-21 promotes M1 and inhibits M2 peritoneal macrophage polarization by directly targeting STAT3 (66). However, it has been also shown that miR-21 inhibits the pro-inflammatory macrophage polarization and enhances the anti-inflammatory macrophage phenotype in other macrophage cell lines $(67,68)$. The reasons for this discrepancy still remain uncertain. Since miRNAs are specific for different tissues and cell types, it is possible that miR-21 exerts different effects on macrophage polarization depending on cell types and in vivo microenvironment. We summarized the similarities and differences in miRNAs that regulate macrophage polarization in mouse and human (Table 2). Furthermore, a single miRNA, such as miR-181a and miR-155, is known to target multiple transcription factors involved in macrophage polarization. In addition, one transcription factor in macrophage polarization also cooperatively binds to various miRNAs, particularly in the cancer microenvironment.

In addition to the canonical function of binding to their target messenger RNAs, tumor-secreted miR-21 and miR-29a may function through other mechanisms, for example, by binding as ligands to receptors of the TLR family, murine TLR7 and human TLR8 in immune cells and triggering a TLR-mediated

TABLE 2 | The effects of microRNAs (miRNAs) on macrophage polarization in mouse and human.

\begin{tabular}{|c|c|c|c|c|}
\hline \multirow[t]{2}{*}{ miRNAs } & \multicolumn{4}{|c|}{ Regulation of macrophage phenotype } \\
\hline & Mouse & Reference & Human & Reference \\
\hline miR-9 & - & & Suppresses M1 & (37) \\
\hline $\operatorname{miR}-27 a$ & $\begin{array}{l}\text { Promotes M1, } \\
\text { suppresses M2 }\end{array}$ & $(40,71)$ & $\begin{array}{l}\text { Promotes M1, } \\
\text { suppresses M2 }\end{array}$ & $(71)$ \\
\hline $\operatorname{miR}-27 b$ & $\begin{array}{l}\text { Promotes M1, } \\
\text { suppresses M2 }\end{array}$ & $(43)$ & $\begin{array}{l}\text { Promotes M1, } \\
\text { suppresses M2 }\end{array}$ & $(43)$ \\
\hline miR-130a & - & & $\begin{array}{l}\text { Promotes M1, } \\
\text { suppresses M2 }\end{array}$ & $(45)$ \\
\hline miR-130b & $\begin{array}{l}\text { Promotes M1, } \\
\text { suppresses M2 }\end{array}$ & $(46)$ & - & \\
\hline $\mathrm{miR}-146 \mathrm{a}$ & $\begin{array}{l}\text { Suppresses M1, } \\
\text { promotes M2 }\end{array}$ & $(48,53)$ & $\begin{array}{l}\text { Suppresses M1, } \\
\text { promotes M2 }\end{array}$ & $(51)$ \\
\hline $\mathrm{miR}-146 b$ & $\begin{array}{l}\text { Suppresses M1, } \\
\text { promotes M2 }\end{array}$ & $(100)$ & $\begin{array}{l}\text { Suppresses M1, } \\
\text { promotes M2 }\end{array}$ & $(54)$ \\
\hline $\operatorname{miR}-155$ & $\begin{array}{l}\text { Promotes M1, } \\
\text { suppresses M2 }\end{array}$ & $(60,64)$ & $\begin{array}{l}\text { Promotes M1, } \\
\text { suppresses M2 }\end{array}$ & $(61-63)$ \\
\hline \multirow[t]{2}{*}{ miR-21 } & $\begin{array}{l}\text { Promotes M1, } \\
\text { suppresses M2 }\end{array}$ & $(66)$ & - & \\
\hline & $\begin{array}{l}\text { Suppresses M1, } \\
\text { promotes M2 }\end{array}$ & $(67,68)$ & - & \\
\hline miR-222-3p & - & & Promotes M2 & (69) \\
\hline miR-19a-3p & Suppresses M2 & (70) & Suppresses M2 & (70) \\
\hline miR-23a & Suppresses M2 & (71) & - & \\
\hline miR-124 & $\begin{array}{l}\text { Suppresses M1, } \\
\text { promotes M2 }\end{array}$ & $(81,82)$ & - & \\
\hline miR-181a & $\begin{array}{l}\text { Suppresses M1, } \\
\text { promotes M2 }\end{array}$ & (83) & $\begin{array}{l}\text { Suppresses M1, } \\
\text { promotes M2 }\end{array}$ & (83) \\
\hline let-7c & $\begin{array}{l}\text { Suppresses M1, } \\
\text { promotes M2 }\end{array}$ & (86) & - & \\
\hline miR-125a & $\begin{array}{l}\text { Promotes M1, } \\
\text { suppresses M2 }\end{array}$ & (98) & - & \\
\hline miR-125b & $\begin{array}{l}\text { Promotes M1, } \\
\text { suppresses M2 }\end{array}$ & (99) & - & \\
\hline miR-93 & $\begin{array}{l}\text { Suppresses M1, } \\
\text { promotes M2 }\end{array}$ & $(96)$ & - & \\
\hline miR-26a & $\begin{array}{l}\text { Promotes M1, } \\
\text { suppresses M2 }\end{array}$ & $(104)$ & Suppresses M2 & $(111,113)$ \\
\hline miR-26b & - & & Suppresses M2 & $(111,113)$ \\
\hline miR-720 & - & & Suppresses M2 & (105) \\
\hline miR-210 & Suppresses M1 & $(109,110)$ & - & \\
\hline
\end{tabular}

-, Not determined. 
prometastatic inflammatory response, to regulate macrophage polarization (65). Lehmann et al. also found that let-7b can act as a potent activator of TLR7 signaling in neurons and this activation may induce neurodegeneration (114). The GU-rich motif (GUUG for miR-21, GGUU for miR-29a, and GUUGUGU for let-7b) is essential for the miRNA-TLR recognition. This may be an important pathway to modulate macrophage polarization. However, whether these miRNAs with "GU" rich sequence can directly bind to transcription factors and regulate macrophage polarization needs further investigation.

The extent of macrophage infiltration serves as an important diagnostic and prognostic biomarker in many human cancers (115). An increased number of $\mathrm{CD}^{+} 8^{+}$(a typical mark of TAMs) macrophages was strongly associated with shortened survival in patients with classic Hodgkin's lymphoma, suggesting a new biomarker for risk stratification (116). High macrophage density at the tumor front positively influences prognosis in colorectal cancer (117). In addition, several lines of evidence indicate that new strategies manipulating TAMs represent an active research area for improving anti-tumor therapies $(118,119)$. TAM depletion was accompanied by significant inhibition of tumor growth in both syngeneic and xenogenic tumor models. Treatment of tumor-bearing mice with clodrolip in combination with antiVEGF single chain fragment antibodies significantly enhanced the depletion of TAMs and resulted in drastic tumor growth inhibition (120). In mice harboring glioblastoma multiforme xenografts, treatment with pexidartinib (PLX3397) augmented

\section{REFERENCES}

1. Edholm ES, Rhoo KH, Robert J. Evolutionary aspects of macrophages polarization. Results Probl Cell Differ (2017) 62:3-22. doi:10.1007/978-3-31954090-0_1

2. Schultze JL, Schmieder A, Goerdt S. Macrophage activation in human diseases. Semin Immunol (2015) 27(4):249-56. doi:10.1016/j.smim.2015.07.003

3. Terry RL, Miller SD. Molecular control of monocyte development. Cell Immunol (2014) 291(1-2):16-21. doi:10.1016/j.cellimm.2014.02.008

4. Chaudhuri A. Regulation of macrophage polarization by RON receptor tyrosine kinase signaling. Front Immunol (2014) 5:546. doi:10.3389/ fimmu.2014.00546

5. Gomez Perdiguero E, Klapproth K, Schulz C, Busch K, Azzoni E, Crozet L, et al. Tissue-resident macrophages originate from yolk-sac-derived erythromyeloid progenitors. Nature (2015) 518(7540):547-51. doi:10.1038/ nature 13989

6. Stremmel C, Schuchert R, Wagner F, Thaler R, Weinberger T, Pick R, et al. Yolk sac macrophage progenitors traffic to the embryo during defined stages of development. Nat Commun (2018) 9(1):75. doi:10.1038/s41467-017-02492-2

7. Hoeffel G, Wang Y, Greter M, See P, Teo P, Malleret B, et al. Adult Langerhans cells derive predominantly from embryonic fetal liver monocytes with a minor contribution of yolk sac-derived macrophages. JExp Med (2012) 209(6):1167-81. doi:10.1084/jem.20120340

8. Sica A, Mantovani A. Macrophage plasticity and polarization: in vivo veritas. J Clin Invest (2012) 122(3):787-95. doi:10.1172/JCI59643

9. Locati M, Mantovani A, Sica A. Macrophage activation and polarization as an adaptive component of innate immunity. Adv Immunol (2013) 120:163-84. doi:10.1016/B978-0-12-417028-5.00006-5

10. Wang $\mathrm{N}$, Liang $\mathrm{H}$, Zen K. Molecular mechanisms that influence the macrophage m1-m2 polarization balance. Front Immunol (2014) 5:614. doi:10.3389/fimmu.2014.00614

11. Liu YC, Zou XB, Chai YF, Yao YM. Macrophage polarization in inflammatory diseases. Int J Biol Sci (2014) 10(5):520-9. doi:10.7150/ijbs.8879 tumor responsiveness to radiotherapy by reducing the recruitment of bone marrow-derived TAMs (121). However, the extent to which their effects on macrophages explain their clinical efficacy still remains to be defined. Understanding the molecular mechanisms for the miRNA-transcription factor networks to regulate macrophages helps provide a basis for macrophagecentered diagnostic and therapeutic strategies.

In view of the importance and multifaceted contribution of macrophage polarization in many physiological and pathological conditions including infection, inflammation, immunity, regeneration, and cancer, more research is required for a better understanding of how multiple target miRNAs are required to modulate transcription factors and how they cooperatively balance macrophage polarization in various diseases.

\section{AUTHOR CONTRIBUTIONS}

G-JZ conceived and designed the article. HL and TJ surveyed the literature and wrote the article. M-QL and X-LZ surveyed the literature and provided suggestions. All the authors have approved the manuscript for submission.

\section{ACKNOWLEDGMENTS}

The authors gratefully acknowledge the financial support from the National Natural Sciences Foundation of China (81660082) and the Guangxi Natural Sciences Foundation (AA139209).

12. Martinez FO, Gordon S. The M1 and M2 paradigm of macrophage activation: time for reassessment. F1000Prime Rep (2014) 6:13. doi:10.12703/P6-13

13. Hao NB, Lu MH, Fan YH, Cao YL, Zhang ZR, Yang SM. Macrophages in tumor microenvironments and the progression of tumors. Clin Dev Immunol (2012) 2012:948098. doi:10.1155/2012/948098

14. Mosser DM, Edwards JP. Exploring the full spectrum of macrophage activation. Nat Rev Immunol (2008) 8(12):958-69. doi:10.1038/nri2448

15. Liao X, Sharma N, Kapadia F, Zhou G, Lu Y, Hong H, et al. Kruppel-like factor 4 regulates macrophage polarization. J Clin Invest (2011) 121(7):2736-49. doi:10.1172/JCI45444

16. Chanmee T, Ontong P, Konno K, Itano N. Tumor-associated macrophages as major players in the tumor microenvironment. Cancers (Basel) (2014) 6(3):1670-90. doi:10.3390/cancers6031670

17. Biswas SK, Chittezhath M, Shalova IN, Lim JY. Macrophage polarization and plasticity in health and disease. Immunol Res (2012) 53(1-3):11-24. doi:10.1007/s12026-012-8291-9

18. Italiani P, Boraschi D. From monocytes to M1/M2 macrophages: phenotypical vs. functional differentiation. Front Immunol (2014) 5:514. doi:10.3389/ fimmu.2014.00514

19. Sica A, Erreni M, Allavena P, Porta C. Macrophage polarization in pathology. Cell Mol Life Sci (2015) 72(21):4111-26. doi:10.1007/s00018-015-1995-y

20. Ruffell B, Affara NI, Coussens LM. Differential macrophage programming in the tumor microenvironment. Trends Immunol (2012) 33(3):119-26. doi:10.1016/j.it.2011.12.001

21. Tugal D, Liao X, Jain MK. Transcriptional control of macrophage polarization. Arterioscler Thromb Vasc Biol (2013) 33(6):1135-44. doi:10.1161/ ATVBAHA.113.301453

22. Lawrence T, Natoli G. Transcriptional regulation of macrophage polarization: enabling diversity with identity. Nat Rev Immunol (2011) 11(11):750-61. doi:10.1038/nri3088

23. Molawi K, Sieweke MH. Transcriptional control of macrophage identity, self-renewal, and function. Adv Immunol (2013) 120:269-300. doi:10.1016/ B978-0-12-417028-5.00010-7 
24. Yang M, Li F, Wang L, Yukht A, Arias A, Tian F, et al. GATA3 regulates macrophage polarization and phenotype. Circulation (2012) 126:A13424.

25. Wu J, Ding J, Yang J, Guo X, Zheng Y. MicroRNA roles in the nuclear factor kappa B signaling pathway in cancer. Front Immunol (2018) 9:546. doi:10.3389/fimmu.2018.00546

26. Weigel NL, Moore NL. Steroid receptor phosphorylation: a key modulator of multiple receptor functions. Mol Endocrinol (2007) 21(10):2311-9. doi:10.1210/me.2007-0101

27. Chawla A, Repa JJ, Evans RM, Mangelsdorf DJ. Nuclear receptors and lipid physiology: opening the X-files. Science (2001) 294(5548):1866-70. doi:10.1126/science.294.5548.1866

28. Iwakawa HO, Tomari Y. The functions of microRNAs: mRNA decay and translational repression. Trends Cell Biol (2015) 25(11):651-65. doi:10.1016/j. tcb.2015.07.011

29. Ebert MS, Sharp PA. Roles for microRNAs in conferring robustness to biological processes. Cell (2012) 149(3):515-24. doi:10.1016/j.cell.2012. 04.005

30. Graff JW, Dickson AM, Clay G, McCaffrey AP, Wilson ME. Identifying functional microRNAs in macrophages with polarized phenotypes. J Biol Chem (2012) 287(26):21816-25. doi:10.1074/jbc.M111.327031

31. Penas F, Mirkin GA, Vera M, Cevey A, Gonzalez CD, Gomez MI, et al. Treatment in vitro with PPARalpha and PPARgamma ligands drives M1-to-M2 polarization of macrophages from T. cruzi-infected mice. Biochim Biophys Acta (2015) 1852(5):893-904. doi:10.1016/j.bbadis.2014.12.019

32. Chawla A. Control of macrophage activation and function by PPARs. Circ Res (2010) 106(10):1559-69. doi:10.1161/CIRCRESAHA.110.216523

33. Kang K, Reilly SM, Karabacak V, Gangl MR, Fitzgerald K, Hatano B, et al. Adipocyte-derived Th2 cytokines and myeloid PPARdelta regulate macrophage polarization and insulin sensitivity. Cell Metab (2008) 7(6):485-95. doi:10.1016/j.cmet.2008.04.002

34. Bouhlel MA, Derudas B, Rigamonti E, Dievart R, Brozek J, Haulon S, et al. PPARgamma activation primes human monocytes into alternative M2 macrophages with anti-inflammatory properties. Cell Metab (2007) 6(2):137-43. doi:10.1016/j.cmet.2007.06.010

35. Chakraborty S, Zawieja DC, Davis MJ, Muthuchamy M. MicroRNA signature of inflamed lymphatic endothelium and role of miR-9 in lymphangiogenesis and inflammation. Am J Physiol Cell Physiol (2015) 309(10):C680-92. doi:10.1152/ajpcell.00122.2015

36. Bazzoni F, Rossato M, Fabbri M, Gaudiosi D, Mirolo M, Mori L, et al. Induction and regulatory function of miR-9 in human monocytes and neutrophils exposed to proinflammatory signals. Proc Natl Acad Sci U S A (2009) 106(13):5282-7. doi:10.1073/pnas.0810909106

37. Thulin P, Wei T, Werngren O, Cheung L, Fisher RM, Grander D, et al. MicroRNA-9 regulates the expression of peroxisome proliferator-activated receptor delta in human monocytes during the inflammatory response. Int J Mol Med (2013) 31(5):1003-10. doi:10.3892/ijmm.2013.1311

38. Bouhlel MA, Brozek J, Derudas B, Zawadzki C, Jude B, Staels B, et al. Unlike PPARgamma, PPARalpha or PPARbeta/delta activation does not promote human monocyte differentiation toward alternative macrophages. Biochem Biophys Res Commun (2009) 386(3):459-62. doi:10.1016/j.bbrc.2009. 06.047

39. Zhang M, Wu JF, Chen WJ, Tang SL, Mo ZC, Tang YY, et al. MicroRNA$27 \mathrm{a} / \mathrm{b}$ regulates cellular cholesterol efflux, influx and esterification/ hydrolysis in THP-1 macrophages. Atherosclerosis (2014) 234(1):54-64. doi:10.1016/j.atherosclerosis.2014.02.008

40. Yao F, Yu Y, Feng L, Li J, Zhang M, Lan X, et al. Adipogenic miR-27a in adipose tissue upregulates macrophage activation via inhibiting PPARgamma of insulin resistance induced by high-fat diet-associated obesity. Exp Cell Res (2017) 355(2):105-12. doi:10.1016/j.yexcr.2017.03.060

41. Chen WJ, Yin K, Zhao GJ, Fu YC, Tang CK. The magic and mystery of microRNA-27 in atherosclerosis. Atherosclerosis (2012) 222(2):314-23. doi:10.1016/j.atherosclerosis.2012.01.020

42. Veliceasa D, Biyashev D, Qin G, Misener S, Mackie AR, Kishore R, et al. Therapeutic manipulation of angiogenesis with miR-27b. Vasc Cell (2015) 7:6. doi:10.1186/s13221-015-0031-1

43. Jennewein C, von Knethen A, Schmid T, Brune B. MicroRNA-27b contributes to lipopolysaccharide-mediated peroxisome proliferator-activated receptor gamma (PPARgamma) mRNA destabilization. J Biol Chem (2010) 285(16):11846-53. doi:10.1074/jbc.M109.066399
44. Kida K, Nakajima M, Mohri T, Oda Y, Takagi S, Fukami T, et al. PPARalpha is regulated by miR-21 and miR-27b in human liver. Pharm Res (2011) 28(10):2467-76. doi:10.1007/s11095-011-0473-y

45. Lin L, Lin H, Wang L, Wang B, Hao X, Shi Y. miR-130a regulates macrophage polarization and is associated with non-small cell lung cancer. Oncol Rep (2015) 34(6):3088-96. doi:10.3892/or.2015.4301

46. Zhang M, Zhou Z, Wang J, Li S. miR-130b promotes obesity associated adipose tissue inflammation and insulin resistance in diabetes mice through alleviating M2 macrophage polarization via repression of PPAR-gamma. Immunol Lett (2016) 180:1-8. doi:10.1016/j.imlet.2016.10.004

47. Wang LL, Huang Y, Wang G, Chen SD. The potential role of microRNA-146 in Alzheimer's disease: biomarker or therapeutic target? Med Hypotheses (2012) 78(3):398-401. doi:10.1016/j.mehy.2011.11.019

48. Vergadi E, Vaporidi K, Theodorakis EE, Doxaki C, Lagoudaki E, Ieronymaki E, et al. Akt2 deficiency protects from acute lung injury via alternative macrophage activation and miR-146a induction in mice. J Immunol (2014) 192(1):394-406. doi:10.4049/jimmunol.1300959

49. Takahashi Y, Satoh M, Minami Y, Tabuchi T, Itoh T, Nakamura M. Expression of miR-146a/b is associated with the toll-like receptor 4 signal in coronary artery disease: effect of renin-angiotensin system blockade and statins on miRNA-146a/b and toll-like receptor 4 levels. Clin Sci (Lond) (2010) 119(9):395-405. doi:10.1042/CS20100003

50. Xu J, Wu W, Zhang L, Dorset-Martin W, Morris MW, Mitchell ME, et al. The role of microRNA-146a in the pathogenesis of the diabetic wound-healing impairment: correction with mesenchymal stem cell treatment. Diabetes (2012) 61(11):2906-12. doi:10.2337/db12-0145

51. Li Y, Zhao L, Shi B, Ma S, Xu Z, Ge Y, et al. Functions of miR-146a and miR-222 in tumor-associated macrophages in breast cancer. Sci Rep (2015) 5:18648. doi:10.1038/srep 18648

52. Curtale G, Mirolo M, Renzi TA, Rossato M, Bazzoni F, Locati M. Negative regulation of toll-like receptor 4 signaling by IL-10-dependent microRNA146b. Proc Natl Acad Sci U S A (2013) 110(28):11499-504. doi:10.1073/ pnas. 1219852110

53. Huang C, Liu XJ, QunZhou XJ, Xie J, Ma TT, Meng XM, et al. miR-146a modulates macrophage polarization by inhibiting Notch1 pathway in RAW264.7 macrophages. Int Immunopharmacol (2016) 32:46-54. doi:10.1016/j. intimp.2016.01.009

54. Chen L, Dai YM, Ji CB, Yang L, Shi CM, Xu GF, et al. miR-146b is a regulator of human visceral preadipocyte proliferation and differentiation and its expression is altered in human obesity. Mol Cell Endocrinol (2014) 393(1-2):65-74. doi:10.1016/j.mce.2014.05.022

55. He C, Medley SC, Hu T, Hinsdale ME, Lupu F, Virmani R, et al. PDGFRbeta signalling regulates local inflammation and synergizes with hypercholesterolaemia to promote atherosclerosis. Nat Commun (2015) 6:7770. doi:10.1038/ ncomms 8770

56. Giles EM, Sanders TJ, McCarthy NE, Lung J, Pathak M, MacDonald TT, et al. Regulation of human intestinal T-cell responses by type 1 interferon-STAT1 signaling is disrupted in inflammatory bowel disease. Mucosal Immunol (2017) 10(1):184-93. doi:10.1038/mi.2016.44

57. Takaishi K, Komohara Y, Tashiro H, Ohtake H, Nakagawa T, Katabuchi H, et al. Involvement of M2-polarized macrophages in the ascites from advanced epithelial ovarian carcinoma in tumor progression via Stat3 activation. Cancer Sci (2010) 101(10):2128-36. doi:10.1111/j.1349-7006.2010.01652.x

58. Stokes K, LaMarche NM, Islam N, Wood A, Huang W, August A. Cutting edge: STAT6 signaling in eosinophils is necessary for development of allergic airway inflammation. J Immunol (2015) 194(6):2477-81. doi:10.4049/ jimmunol.1402096

59. Hu X, Chakravarty SD, Ivashkiv LB. Regulation of interferon and toll-like receptor signaling during macrophage activation by opposing feedforward and feedback inhibition mechanisms. Immunol Rev (2008) 226:41-56. doi:10.1111/j.1600-065X.2008.00707.x

60. Xu F, Kang Y, Zhang H, Piao Z, Yin H, Diao R, et al. Akt1-mediated regulation of macrophage polarization in a murine model of Staphylococcus aureus pulmonary infection. J Infect Dis (2013) 208(3):528-38. doi:10.1093/infdis/ jit177

61. Martinez-Nunez RT, Louafi F, Sanchez-Elsner T. The interleukin 13 (IL-13) pathway in human macrophages is modulated by microRNA- 155 via direct targeting of interleukin 13 receptor alphal (IL13Ralpha1). J Biol Chem (2011) 286(3):1786-94. doi:10.1074/jbc.M110.169367 
62. Moore CS, Rao VT, Durafourt BA, Bedell BJ, Ludwin SK, Bar-Or A, et al. miR-155 as a multiple sclerosis-relevant regulator of myeloid cell polarization. Ann Neurol (2013) 74(5):709-20. doi:10.1002/ana.23967

63. Kutty RK, Nagineni CN, Samuel W, Vijayasarathy C, Hooks JJ, Redmond TM. Inflammatory cytokines regulate microRNA-155 expression in human retinal pigment epithelial cells by activating JAK/STAT pathway. Biochem Biophys Res Commun (2010) 402(2):390-5. doi:10.1016/j.bbrc.2010.10.042

64. Zhang Y, Zhang M, Li X, Tang Z, Wang X, Zhong M, et al. Silencing microRNA-155 attenuates cardiac injury and dysfunction in viral myocarditis via promotion of M2 phenotype polarization of macrophages. Sci Rep (2016) 6:22613. doi:10.1038/srep22613

65. Fabbri M, Paone A, Calore F, Galli R, Gaudio E, Santhanam R, et al. MicroRNAs bind to toll-like receptors to induce prometastatic inflammatory response. Proc Natl Acad Sci U S A (2012) 109(31):E2110-6. doi:10.1073/ pnas.1209414109

66. Wang Z, Brandt S, Medeiros A, Wang S, Wu H, Dent A, et al. MicroRNA 21 is a homeostatic regulator of macrophage polarization and prevents prostaglandin E2-mediated M2 generation. PLoS One (2015) 10(2):e0115855. doi:10.1371/journal.pone.0115855

67. Caescu CI, Guo X, Tesfa L, Bhagat TD, Verma A, Zheng D, et al. Colony stimulating factor-1 receptor signaling networks inhibit mouse macrophage inflammatory responses by induction of microRNA-21. Blood (2015) 125(8):e1-13. doi:10.1182/blood-2014-10-608000

68. Lu TX, Munitz A, Rothenberg ME. MicroRNA-21 is up-regulated in allergic airway inflammation and regulates IL-12p35 expression. J Immunol (2009) 182(8):4994-5002. doi:10.4049/jimmunol.0803560

69. Ying X, Wu Q, Wu X, Zhu Q, Wang X, Jiang L, et al. Epithelial ovarian cancer-secreted exosomal miR-222-3p induces polarization of tumorassociated macrophages. Oncotarget (2016) 7(28):43076-87. doi:10.18632/ oncotarget.9246

70. Yang J, Zhang Z, Chen C, Liu Y, Si Q, Chuang TH, et al. MicroRNA-19a-3p inhibits breast cancer progression and metastasis by inducing macrophage polarization through downregulated expression of Fra-1 proto-oncogene. Oncogene (2014) 33(23):3014-23. doi:10.1038/onc.2013.258

71. Ma S, Liu M, Xu Z, Li Y, Guo H, Ge Y, et al. A double feedback loop mediated by microRNA-23a/27a/24-2 regulates M1 versus M2 macrophage polarization and thus regulates cancer progression. Oncotarget (2016) 7(12): 13502-19. doi:10.18632/oncotarget.6284

72. Lu YC, Kim I, Lye E, Shen F, Suzuki N, Suzuki S, et al. Differential role for c-Rel and C/EBPbeta/delta in TLR-mediated induction of proinflammatory cytokines. J Immunol (2009) 182(11):7212-21. doi:10.4049/jimmunol. 0802971

73. Lee B, Qiao L, Lu M, Yoo HS, Cheung W, Mak R, et al. C/EBPalpha regulates macrophage activation and systemic metabolism. Am J Physiol Endocrinol Metab (2014) 306(10):E1144-54. doi:10.1152/ajpendo.00002.2014

74. Litvak V, Ramsey SA, Rust AG, Zak DE, Kennedy KA, Lampano AE, et al. Function of C/EBPdelta in a regulatory circuit that discriminates between transient and persistent TLR4-induced signals. Nat Immunol (2009) 10(4):437-43. doi:10.1038/ni.1721

75. Tada Y, Brena RM, Hackanson B, Morrison C, Otterson GA, Plass C. Epigenetic modulation of tumor suppressor CCAAT/enhancer binding protein alpha activity in lung cancer. J Natl Cancer Inst (2006) 98(6):396-406. doi:10.1093/jnci/djj093

76. Bennett KL, Hackanson B, Smith LT, Morrison CD, Lang JC, Schuller DE, et al. Tumor suppressor activity of CCAAT/enhancer binding protein alpha is epigenetically down-regulated in head and neck squamous cell carcinoma. Cancer Res (2007) 67(10):4657-64. doi:10.1158/0008-5472.CAN-06-4793

77. Lin TC, Hou HA, Chou WC, Ou DL, Yu SL, Tien HF, et al. CEBPA methylation as a prognostic biomarker in patients with de novo acute myeloid leukemia. Leukemia (2011) 25(1):32-40. doi:10.1038/leu.2010.222

78. Kim N, Choi S, Lim C, Lee H, Oh J. Albumin mediates PPAR-gamma or C/ EBP-alpha-induced phenotypic changes in pancreatic stellate cells. Biochem Biophys Res Commun (2010) 391(1):640-4. doi:10.1016/j.bbrc.2009.11.112

79. Ramji DP, Foka P. CCAAT/enhancer-binding proteins: structure, function and regulation. Biochem J (2002) 365(Pt 3):561-75. doi:10.1042/bj20020508

80. Ali AT, Hochfeld WE, Myburgh R, Pepper MS. Adipocyte and adipogenesis. Eur J Cell Biol (2013) 92(6-7):229-36. doi:10.1016/j.ejcb.2013.06.001

81. Yu A, Zhang T, Duan H, Pan Y, Zhang X, Yang G, et al. miR-124 contributes to M2 polarization of microglia and confers brain inflammatory protection via the C/EBP-alpha pathway in intracerebral hemorrhage. Immunol Lett (2017) 182:1-11. doi:10.1016/j.imlet.2016.12.003

82. Ponomarev ED, Veremeyko T, Barteneva N, Krichevsky AM, Weiner HL. MicroRNA-124 promotes microglia quiescence and suppresses EAE by deactivating macrophages via the C/EBP-alpha-PU.1 pathway. Nat Med (2011) 17(1):64-70. doi:10.1038/nm.2266

83. Bi J, Zeng X, Zhao L, Wei Q, Yu L, Wang X, et al. miR-181a induces macrophage polarized to M2 phenotype and promotes M2 macrophage-mediated tumor cell metastasis by targeting KLF6 and C/EBPalpha. Mol Ther Nucleic Acids (2016) 5(9):e368. doi:10.1038/mtna.2016.71

84. He M, Xu Z, Ding T, Kuang DM, Zheng L. MicroRNA-155 regulates inflammatory cytokine production in tumor-associated macrophages via targeting C/EBPbeta. Cell Mol Immunol (2009) 6(5):343-52. doi:10.1038/cmi.2009.45

85. Arranz A, Doxaki C, Vergadi E, Martinez de la Torre Y, Vaporidi K, Lagoudaki ED, et al. Akt1 and Akt2 protein kinases differentially contribute to macrophage polarization. Proc Natl Acad Sci U S A (2012) 109(24): 9517-22. doi:10.1073/pnas.1119038109

86. Banerjee S, Xie N, Cui H, Tan Z, Yang S, Icyuz M, et al. MicroRNA let-7c regulates macrophage polarization. J Immunol (2013) 190(12):6542-9. doi:10.4049/jimmunol.1202496

87. Li D, Guabiraba R, Besnard AG, Komai-Koma M, Jabir MS, Zhang L, et al. IL-33 promotes ST2-dependent lung fibrosis by the induction of alternatively activated macrophages and innate lymphoid cells in mice. J Allergy Clin Immunol (2014) 134(6):1422-32.e11. doi:10.1016/j.jaci.2014.05.011

88. Romero F, Shah D, Duong M, Penn RB, Fessler MB, Madenspacher J, et al. A pneumocyte-macrophage paracrine lipid axis drives the lung toward fibrosis. Am J Respir Cell Mol Biol (2015) 53(1):74-86. doi:10.1165/ rcmb.2014-0343OC

89. Tao B, Jin W, Xu J, Liang Z, Yao J, Zhang Y, et al. Myeloid-specific disruption of tyrosine phosphatase Shp2 promotes alternative activation of macrophages and predisposes mice to pulmonary fibrosis. J Immunol (2014) 193(6): 2801-11. doi:10.4049/jimmunol.1303463

90. Hoeksema MA, Stoger JL, de Winther MP. Molecular pathways regulating macrophage polarization: implications for atherosclerosis. Curr Atheroscler Rep (2012) 14(3):254-63. doi:10.1007/s11883-012-0240-5

91. El Chartouni C, Schwarzfischer L, Rehli M. Interleukin-4 induced interferon regulatory factor (Irf) 4 participates in the regulation of alternative macrophage priming. Immunobiology (2010) 215(9-10):821-5. doi:10.1016/j. imbio.2010.05.031

92. Satoh T, Takeuchi O, Vandenbon A, Yasuda K, Tanaka Y, Kumagai Y, et al. The Jmjd3-Irf4 axis regulates M2 macrophage polarization and host responses against helminth infection. Nat Immunol (2010) 11(10):936-44. doi:10.1038/ ni. 1920

93. Dalmas E, Toubal A, Alzaid F, Blazek K, Eames HL, Lebozec K, et al. Irf5 deficiency in macrophages promotes beneficial adipose tissue expansion and insulin sensitivity during obesity. Nat Med (2015) 21(6):610-8. doi:10.1038/ nm.3829

94. Krausgruber T, Blazek K, Smallie T, Alzabin S, Lockstone H, Sahgal N, et al. IRF5 promotes inflammatory macrophage polarization and TH1-TH17 responses. Nat Immunol (2011) 12(3):231-8. doi:10.1038/ni.1990

95. Rauch I, Rosebrock F, Hainzl E, Heider S, Majoros A, Wienerroither S, et al. Noncanonical effects of IRF9 in intestinal inflammation: more than type I and type III interferons. Mol Cell Biol (2015) 35(13):2332-43. doi:10.1128/ MCB.01498-14

96. Ganta VC, Choi MH, Kutateladze A, Fox TE, Farber CR, Annex BH. A microRNA93-interferon regulatory factor-9-immunoresponsive gene-1itaconic acid pathway modulates M2-like macrophage polarization to revascularize ischemic muscle. Circulation (2017) 135(24):2403-25. doi:10.1161/ CIRCULATIONAHA.116.025490

97. Franklin RA, Liao W, Sarkar A, Kim MV, Bivona MR, Liu K, et al. The cellular and molecular origin of tumor-associated macrophages. Science (2014) 344(6186):921-5. doi:10.1126/science.1252510

98. Zhao JL, Huang F, He F, Gao CC, Liang SQ, Ma PF, et al. Forced activation of notch in macrophages represses tumor growth by upregulating miR-125a and disabling tumor-associated macrophages. Cancer Res (2016) 76(6): 1403-15. doi:10.1158/0008-5472.CAN-15-2019

99. Chaudhuri AA, So AY, Sinha N, Gibson WS, Taganov KD, O'Connell RM, et al. MicroRNA-125b potentiates macrophage activation. J Immunol (2011) 187(10):5062-8. doi:10.4049/jimmunol.1102001 
100. Peng L, Zhang H, Hao Y, Xu F, Yang J, Zhang R, et al. Reprogramming macrophage orientation by microRNA 146b targeting transcription factor IRF5. EBioMedicine (2016) 14:83-96. doi:10.1016/j.ebiom.2016.10.041

101. Goodman WA, Omenetti S, Date D, Di Martino L, De Salvo C, Kim GD, et al. KLF6 contributes to myeloid cell plasticity in the pathogenesis of intestinal inflammation. Mucosal Immunol (2016) 9(5):1250-62. doi:10.1038/ mi.2016.1

102. Date D, Das R, Narla G, Simon DI, Jain MK, Mahabeleshwar GH. Kruppellike transcription factor 6 regulates inflammatory macrophage polarization. J Biol Chem (2014) 289(15):10318-29. doi:10.1074/jbc.M113.526749

103. Mege JL, Mehraj V, Capo C. Macrophage polarization and bacterial infections. Curr Opin Infect Dis (2011) 24(3):230-4. doi:10.1097/ QCO.0b013e328344b73e

104. Sahu SK, Kumar M, Chakraborty S, Banerjee SK, Kumar R, Gupta P, et al. MicroRNA 26a (miR-26a)/KLF4 and CREB-C/EBPbeta regulate innate immune signaling, the polarization of macrophages and the trafficking of Mycobacterium tuberculosis to lysosomes during infection. PLoS Pathog (2017) 13(5):e1006410. doi:10.1371/journal.ppat.1006410

105. Zhong Y, Yi C. MicroRNA-720 suppresses M2 macrophage polarization by targeting GATA3. Biosci Rep (2016) 36(4):e00363. doi:10.1042/bsr20160105

106. Bonizzi G, Karin M. The two NF-kappaB activation pathways and their role in innate and adaptive immunity. Trends Immunol (2004) 25(6):280-8. doi:10.1016/j.it.2004.03.008

107. Baker RG, Hayden MS, Ghosh S. NF-kappaB, inflammation, and metabolic disease. Cell Metab (2011) 13(1):11-22. doi:10.1016/j.cmet.2010.12.008

108. Zhu HT, Bian C, Yuan JC, Chu WH, Xiang X, Chen F, et al. Curcumin attenuates acute inflammatory injury by inhibiting the TLR4/MyD88/ NF-kappaB signaling pathway in experimental traumatic brain injury. J Neuroinflammation (2014) 11:59. doi:10.1186/1742-2094-11-59

109. Zhang D, Cao X, Li J, Zhao G. miR-210 inhibits NF-kappaB signaling pathway by targeting DR6 in osteoarthritis. Sci Rep (2015) 5:12775. doi:10.1038/ srep 12775

110. Qi J, Qiao Y, Wang P, Li S, Zhao W, Gao C. MicroRNA-210 negatively regulates LPS-induced production of proinflammatory cytokines by targeting NF-kappaB1 in murine macrophages. FEBS Lett (2012) 586(8):1201-7. doi:10.1016/j.febslet.2012.03.011

111. Pello OM, De Pizzol M, Mirolo M, Soucek L, Zammataro L, Amabile A, et al. Role of c-MYC in alternative activation of human macrophages and tumor-associated macrophage biology. Blood (2012) 119(2):411-21. doi:10.1182/blood-2011-02-339911

112. Pello OM, Chevre R, Laoui D, De Juan A, Lolo F, Andres-Manzano MJ, et al. In vivo inhibition of c-MYC in myeloid cells impairs tumor-associated macrophage maturation and pro-tumoral activities. PLoS One (2012) 7(9):e45399. doi:10.1371/journal.pone.0045399

113. Li J, Liang Y, Lv H, Meng H, Xiong G, Guan X, et al. miR-26a and miR-26b inhibit esophageal squamous cancer cell proliferation through suppression of c-MYC pathway. Gene (2017) 625:1-9. doi:10.1016/j.gene.2017.05.001

114. Lehmann SM, Kruger C, Park B, Derkow K, Rosenberger K, Baumgart J, et al. An unconventional role for miRNA: let-7 activates toll-like receptor 7 and causes neurodegeneration. Nat Neurosci (2012) 15(6):827-35. doi:10.1038/ nn. 3113

115. Poh AR, Ernst M. Targeting macrophages in cancer: from bench to bedside. Front Oncol (2018) 8:49. doi:10.3389/fonc.2018.00049

116. Steidl C, Lee T, Shah SP, Farinha P, Han G, Nayar T, et al. Tumor-associated macrophages and survival in classic Hodgkin's lymphoma. N Engl J Med (2010) 362(10):875-85. doi:10.1056/NEJMoa0905680

117. Forssell J, Oberg A, Henriksson ML, Stenling R, Jung A, Palmqvist R. High macrophage infiltration along the tumor front correlates with improved survival in colon cancer. Clin Cancer Res (2007) 13(5):1472-9. doi:10.1158/10780432.CCR-06-2073

118. Ostuni R, Kratochvill F, Murray PJ, Natoli G. Macrophages and cancer: from mechanisms to therapeutic implications. Trends Immunol (2015) 36(4):229-39. doi:10.1016/j.it.2015.02.004

119. Mantovani A, Allavena P. The interaction of anticancer therapies with tumor-associated macrophages. J Exp Med (2015) 212(4):435-45. doi:10.1084/ jem.20150295

120. Zeisberger SM, Odermatt B, Marty C, Zehnder-Fjallman AH, Ballmer-Hofer K, Schwendener RA. Clodronate-liposome-mediated depletion of tumourassociated macrophages: a new and highly effective antiangiogenic therapy approach. Br J Cancer (2006) 95(3):272-81. doi:10.1038/sj.bjc.6603240

121. Stafford JH, Hirai T, Deng L, Chernikova SB, Urata K, West BL, et al. Colony stimulating factor 1 receptor inhibition delays recurrence of glioblastoma after radiation by altering myeloid cell recruitment and polarization. Neuro Oncol (2016) 18(6):797-806. doi:10.1093/neuonc/nov272

Conflict of Interest Statement: The authors declare that there is no conflict of interests regarding the publication of this paper.

Copyright (c) $2018 \mathrm{Li}$, Jiang, Li, Zheng and Zhao. This is an open-access article distributed under the terms of the Creative Commons Attribution License (CC BY). The use, distribution or reproduction in other forums is permitted, provided the original author(s) and the copyright owner are credited and that the original publication in this journal is cited, in accordance with accepted academic practice. No use, distribution or reproduction is permitted which does not comply with these terms. 